\title{
EFFECT OF HBM REHABILITATION EXERCISES ON DEPRESSION, ANXIETY AND HEALTH BELIEF IN ELDERLY PATIENTS WITH OSTEOPOROTIC FRACTURE
}

\author{
Ming Zhang \\ Department of Physical Education, Nanjing Sport Institute, Nanjing, Jiangsu, China \\ received: 13.9.2017; \\ revised: 25.10 .2017 ; \\ accepted: 30.10 .2017
}

\begin{abstract}
SUMMARY
Background: Guided by the health belief model (HBM), this study provided elderly patients with osteoporotic fracture with health education concerning osteoporosis $(O P)$ prevention, carried out rehabilitation exercises based on HBM, and evaluated the intervention effect of HBM rehabilitation exercises, to offer a scientific basis for improving the prognosis of elderly patients with OP fracture.

Subjects and methods: A total of 162 elderly patients with OP fracture treated in three third-grade general hospitals of Jiangsu Province from January 2016 to September 2016 participated in this study. According to the minimization random allocation method, the patients were divided into two groups: the conventional rehabilitation group and the HBM rehabilitation group, with 81 patients in each group. After three months of intervention, the two groups were compared in terms of anxiety, depression, OP knowledge, and OP health belief.

Results: After 3 months of intervention, the anxiety and depression scores decreased in both groups. Both anxiety and depression scores of the HBM rehabilitation group were higher than those of the conventional rehabilitation group, with statistically significant differences $(P<0.001)$. The increases in the OP knowledge score and OP health belief score of the HBM rehabilitation group were higher than those of the conventional rehabilitation group, with statistically significant differences $(P<0.001)$.

Conclusions: HBM-based rehabilitation exercises alleviate negative emotions in elderly patients with osteoporotic fracture and improve their OP knowledge and health belief scores.
\end{abstract}

Key words: health belief model (HBM) - negative emotions - depression - anxiety - osteoporotic fracture

$* * * * *$

\section{INTRODUCTION}

In China, the number of elderly people has increased dramatically. According to the 2015 national census, 222 million people aged 60 and above live in China, accounting for $16.1 \%$ of the population, and 143.86 million people aged 65 and above, accounting for $10.5 \%$ of the total population (Sha 2016). Consequently, China has one of the largest populations of elderly people in the world. With increasing age, elderly people generally suffer progressive degradation in physiological functions and organs, organization, morphology, and other aspects, resulting in metabolic disorders and weakened performance of physiological functions (Ang \& Madsen 2015). Osteoporosis, which is caused by bone degeneration, has become an urgent problem due to its high incidence and serious consequences (Srichuae et al. 2016). Osteoporosis $(\mathrm{OP})$ refers to a systemic skeletal disease resulting from a variety of causes and is characterized by low bone mass and bone microstructure degeneration, accompanied by increased bone fragility and fracture tendency (Burge et al. 2007). At present, there are about 200 million people worldwide who suffer from OP, and its incidence rate has leaped to seventh place among various common diseases. Among postmenopausal women and elderly people, OP demonstrates a high rate of incidence, rate of disability, rate of mortality, and health care costs. Fracture is the most common and serious complication of elderly patients with $\mathrm{OP}$, and the most common first symptom for which elderly patients seek medical treatment (Lupescu \& Marcov 2016).

Elderly osteoporotic fractures are mostly emergencies, sudden and unexpected personal injuries that bring about unpredictable consequences. Restricted physical activities due to limb fractures and a long treatment process place a heavy psychological burden on patients, leading to nervousness, anxiety, fear, depression and irritability, which undermine patients' treatment (Wang et al. 2010). Due to their physical and psychological fragility, the elderly are prone to anxiety, depression, and other negative emotional reactions in a sudden fracture event. If correct fracture rehabilitation guidance is not offered, their prognosis will be affected. Studies found that giving appropriate rehabilitation guidance and assistance to patients with post-fracture anxiety and depression supports their rehabilitation and treatment. According to a survey, only $4.1 \%$ of elderly people in China have a comprehensive understanding of OP fracture and other related knowledge. Because of the significant positive correlation between OP fracture knowledge and prognosis, the lack of relevant knowledge among the elderly has made it difficult for them to cooperate with doctors during treatment, so that the risk of recurrence is greatly increased (Wang et al. 2014). In addition, the healing process for elderly people with OP fracture is slow. Because the patients lack knowledge and other factors, the disease tends to be ignored. Without timely treatment and health guidance, multiple 
body fractures might follow, seriously affecting elderly people's quality of life and further exacerbating their negative emotions (Ballesta 2017).

The health belief model (HBM) was developed and revised by Bercker and other social psychologists on the basis of the psychological theories of motivation, cognition, and value expectation (Rosenstock 1974). This model emphasizes the role of the individual's subjective psychological process (i.e., expectation, thinking, reasoning, belief, etc.) in behaviors, stating that changing health beliefs can effectively change health behaviors (Straub \& Leahy 2015). As the model succeeds in explaining the effect of various psychosocial factors on behaviors, in particular, predicting which factors affect people's compliance with medical advice, it has been widely applied in preventive health care and health education. For example, Huang et al. (2013) studied the influence of HBM education on disease awareness and respiratory function exercise compliance of COPD patients. Sun et al. (2016) suggested that some exercise measures taken through HBM can improve self-efficacy, reduce subjective and objective obstacles, and to promote the physical activity of hypertensive patients. Huang et al. (2010) used HBM for health education, which improved patients' compliance, promoted joint function, reduced the incidence of postoperative complications, and increased patients' quality of life. Currently, there are few empirical studies on the application of HMB in rehabilitating elderly patients with osteoporotic fracture through exercise. In this study, the HBM-based rehabilitation exercise strategy was adopted to observe its effect on negative emotions, such as health belief, anxiety, and depression, in patients with fracture, to provide theoretical support for exploring more effective rehabilitation exercise methods for OP fracture.

\section{SUBJECTS AND METHODS}

\section{Patients}

A total of 162 elderly patients with OP fracture who were treated in three third-grade general hospitals of Jiangsu Province (i.e. Jiangsu Province Hospital, Nanjing General Hospital, and Nanjing Drum Tower Hospital) participated in this study from January 2016 to September 2016. According to the minimization random allocation method, the patients were divided into a conventional rehabilitation group and an HBM rehabilitation group by gender, age, and fracture site as the balance factors, with 81 patients in each group. The study was approved by the hospitals' ethics committees. All the participants were aware of the main methodology and content of this study, took part in the study voluntarily, and signed the informed consent.

\section{Method}

All patients in the two groups underwent open reduction and internal fixation surgery during the three months of intervention.

\section{Conventional rehabilitation group}

The control group underwent conventional rehabilitation methods and was offered psychological care to alleviate common psychological problems, which covered enhancing health education, maintaining harmonious doctor-patient relationships, mobilizing positive society and family factors, reasonable rehabilitation guidance, and other contents (Hu et al. 2009).

\section{HBM rehabilitation group}

The observation group underwent HBM with a rehabilitation team composed of four rehabilitation exercise specialists and two graduate students majoring in sports and exercise science provided elderly OP fracture patients with unified training on rehabilitation exercise methods, significant psychological problems, and HBM-related knowledge. They established trusting relationships, respected the patients' wishes, and used HBM for rehabilitation exercise guidance according to problem progression. 1) Collecting problems: Through communicating and accessing relevant rehabilitation records, they collected objective and comprehensive data about the patients, reassured them that the surgery was safe, and encouraged them to understand and use their positive traits. 2) Setting goals: After developing an in-depth understanding of patients' and their family members' needs during rehabilitation, as well as their expectations for the future, they worked together to set feasible rehabilitation goals. For instance, those who would undergo an upper limb surgery were guided to practice using only one hand before the surgery; those who would undergo a lower limb or lumbar surgery, or needed long-term postoperative bedrest were encouraged to practice self-care skills such as defecating and turning over in bed to enhance their determination to achieve their goals. 3) Exploring accidents: The patients were encouraged to acknowledge the fracture's impact on them and their family, so that the patients could approach it from another point of view. For example, they might be told, "Although it was an unfortunate event, maybe you will have an unexpected harvest. After experiencing this event, you will be more grateful for your relatives and friends, give more care and love to your family, learn to enjoy family life, or take pleasure in the warmth of home." 4) Timely feedback: Full recognition was given to the patients and their caregivers for their efforts because timely, positive feedback can increase a patient's initiative to accomplish their goals. If there was no obvious effect, the goals were readjusted. 5) Distributing the Handbook for Adjusting Lifestyle and Preventing Osteoporosis, prepared by the third-grade hospital where the researcher was working: In addition to the contents distributed to the control group, educational material was also presented during regular lectures for the experiment group. 


\section{Measuring Tools}

- The self-rating depression scale (SDS), compiled by Zung (1965), consists of 20 items, with scores from 1 to 4 for each item. The raw score is the sum of the scores for all items, and the standard score equals the product of the raw score and 1.25. The cutoff value for the SDS standard score is 53 points, with 53-62 points indicating mild depression, 63-72 points indicating moderate depression, and $>72$ points indicating severe depression.

- The self-rating anxiety scale (SAS), compiled by Zung (1971), consists of 20 items, with scores from 1 to 4 for each item. The raw score is the sum of the scores for all items, and the standard score equals the product of the raw score and 1.25. The cutoff value for the SDS standard score is 50 points, with $50-59$ points indicating mild anxiety, 60-69 points indicating moderate anxiety, and $>69$ points indicating severe anxiety.

- The OP knowledge test (OKT), compiled by Kim et al. (1991), consists of three parts: knowledge of OP risk factors, knowledge of exercise, and knowledge of calcium. The scoring range is from 0 to 26 points, and a higher score indicates a higher level of OPrelated knowledge.

- The OP health belief scale, compiled by Chen et al. (2005), consists of 42 items and includes 7 subscales, namely OP susceptibility, severity, exercise benefits, calcium absorption benefits, movement disorders, calcium absorption disorders, and health motivation. The score of each subscale ranges from 6 to 30 points, and the total score ranges from 42 to 210 points. A higher score indicates higher health belief.

\section{Statistical Methods}

The data were analyzed by SPSS 16.0 statistical software. The quantitative data were expressed as mean \pm standard deviation. Cross-group comparison of the means of the two groups was conducted by use of independent sample $t$ tests, and intergroup comparison was carried out with paired $t$ tests. The qualitative data were expressed by the number of cases. A chi-squared test or rank-sum test was used for cross-group comparisons, with $P<0.05$ indicating a statistically significant difference.

\section{Quality Control}

All the investigators were required to complete a unified training before the investigation, memorize the operation content, have good communication skills, and high information sensitivity. The questionnaire was distributed and collected at a certain time, accompanied by unified guidance. Logical proofreading, error correction, and dual-track entry were combined for data collection. The collected questionnaires were subject to strict review, and those with incomplete information and sloppy filling (such as choosing the same answer for all items) were excluded.

\section{RESULTS}

\section{Patient demographics}

The demographics of the study participants are shown in Table 1 . There were no statistically significantly differences $(P>0.05)$ between groups in terms of age, gender, educational level, BMI, fracture site, or family economic situation.

Table 1. Demographics of the research participants

\begin{tabular}{|c|c|c|c|c|c|}
\hline & & $\begin{array}{c}\text { Conventional } \\
\text { Rehabilitation Group } \\
(\mathrm{n}=81)\end{array}$ & $\begin{array}{l}\text { HBM Rehabilitation } \\
\text { Group } \\
(\mathrm{n}=81)\end{array}$ & $t / \chi^{2} / Z$ & $P$ \\
\hline Age & & $67.5 \pm 5.1$ & $68.2 \pm 6.1$ & 0.792 & 0.429 \\
\hline Gender & $\begin{array}{l}\text { Male } \\
\text { Female }\end{array}$ & $\begin{array}{l}36 \\
45\end{array}$ & $\begin{array}{l}35 \\
46\end{array}$ & 0.025 & 0.874 \\
\hline Education & $\begin{array}{l}\text { Junior high school and below } \\
\text { Senior high school or polytechnic school } \\
\text { College and above }\end{array}$ & $\begin{array}{l}34 \\
22 \\
25\end{array}$ & $\begin{array}{l}37 \\
20 \\
24\end{array}$ & 0.386 & 0.700 \\
\hline BMI & & $26.5 \pm 4.3$ & $27.2 \pm 4.7$ & 0.989 & 0.324 \\
\hline Fracture site & $\begin{array}{l}\text { Hip } \\
\text { Tibia and ankle } \\
\text { Proximal humerus } \\
\text { Distal radius } \\
\text { Thoracolumbar } \\
\text { Other }\end{array}$ & $\begin{array}{r}27 \\
18 \\
14 \\
10 \\
6 \\
6\end{array}$ & $\begin{array}{r}26 \\
19 \\
13 \\
12 \\
7 \\
4\end{array}$ & 0.742 & 0.981 \\
\hline $\begin{array}{l}\text { Family } \\
\text { economic } \\
\text { situation }\end{array}$ & $\begin{array}{l}\text { Poor } \\
\text { Slightly poor } \\
\text { Average } \\
\text { Rich } \\
\text { Very rich }\end{array}$ & $\begin{array}{l}12 \\
19 \\
21 \\
14 \\
15\end{array}$ & $\begin{array}{l}11 \\
19 \\
24 \\
14 \\
13\end{array}$ & 0.098 & 0.922 \\
\hline
\end{tabular}


Table 2. Comparison of SAS before and after intervention

\begin{tabular}{lccccc}
\hline & $\begin{array}{c}\text { Before } \\
\text { intervention }\end{array}$ & $\begin{array}{c}\text { After } \\
\text { intervention }\end{array}$ & $\begin{array}{c}\text { Difference before } \\
\text { and after } \\
\text { intervention }\end{array}$ & $\begin{array}{c}P \text { value of } \\
\text { compared } \\
\text { within groups }\end{array}$ & $\begin{array}{c}P \text { value of } \\
\text { comparison } \\
\text { between group }\end{array}$ \\
\hline $\begin{array}{l}\text { Conventional rehabilitation group } \\
\text { HBM rehabilitation group }\end{array}$ & $59.3 \pm 7.9$ & $50.7 \pm 8.7$ & $8.6 \pm 6.4$ & $<0.001$ & $<0.001$ \\
\hline
\end{tabular}

Table 3. Comparison of SDS before and after intervention

\begin{tabular}{lccccc}
\hline & $\begin{array}{c}\text { Before } \\
\text { intervention }\end{array}$ & $\begin{array}{c}\text { After } \\
\text { intervention }\end{array}$ & $\begin{array}{c}\text { Difference before } \\
\text { and after } \\
\text { intervention }\end{array}$ & $\begin{array}{c}P \text { value of } \\
\text { compared } \\
\text { within groups }\end{array}$ & $\begin{array}{c}P \text { value of } \\
\text { comparison } \\
\text { between group }\end{array}$ \\
\hline Conventional rehabilitation group & $62.3 \pm 7.2$ & $54.7 \pm 8.1$ & $7.6 \pm 6.5$ & $<0.001$ & $<0.001$ \\
HBM rehabilitation group & $63.2 \pm 9.1$ & $50.4 \pm 8.4$ & $12.8 \pm 7.0$ & $<0.001$ & \\
\hline
\end{tabular}

Table 4. Comparison of OP knowledge scores before and after intervention

\begin{tabular}{lccccc}
\hline & $\begin{array}{c}\text { Before } \\
\text { intervention }\end{array}$ & $\begin{array}{c}\text { After } \\
\text { intervention }\end{array}$ & $\begin{array}{c}\text { Difference before } \\
\text { and after } \\
\text { intervention }\end{array}$ & $\begin{array}{c}P \text { value of } \\
\text { compared } \\
\text { within groups }\end{array}$ & $\begin{array}{c}P \text { value of } \\
\text { comparison } \\
\text { between group }\end{array}$ \\
\hline Conventional rehabilitation group & $13.3 \pm 3.2$ & $17.7 \pm 4.1$ & $4.4 \pm 3.5$ & $<0.001$ & $<0.001$ \\
HBM rehabilitation group & $14.2 \pm 3.1$ & $20.4 \pm 4.4$ & $6.2 \pm 3.0$ & $<0.001$ & $<$ \\
\hline
\end{tabular}

Table 5. Comparison of OP health belief scores before and after intervention

\begin{tabular}{lccccc}
\hline & $\begin{array}{c}\text { Before } \\
\text { intervention }\end{array}$ & $\begin{array}{c}\text { After } \\
\text { intervention }\end{array}$ & $\begin{array}{c}\text { Difference before } \\
\text { and after } \\
\text { intervention }\end{array}$ & $\begin{array}{c}P \text { value of } \\
\text { compared } \\
\text { within groups }\end{array}$ & $\begin{array}{c}P \text { value of } \\
\text { comparison } \\
\text { between group }\end{array}$ \\
\hline Conventional rehabilitation group & $125.3 \pm 27.7$ & $164.7 \pm 28.1$ & $39.4 \pm 26.5$ & $<0.001$ & $<0.001$ \\
HBM rehabilitation group & $118.5 \pm 29.3$ & $175.4 \pm 31.4$ & $56.9 \pm 27.0$ & $<0.001$ & $<$ \\
\hline
\end{tabular}

\section{Comparison of SAS before and after intervention}

Table 2 shows that there was no statistically significant difference between the SAS scores of the two groups before intervention $(t=1.867, P=0.064)$. After 3 months of intervention, the SAS scores of the two groups were lower, and the differences between the corresponding values before intervention were statistically significant $(P<0.05)$; the decreases in their SAS scores, higher in the HBM rehabilitation group than in the conventional rehabilitation group, are statistically significantly different $(t=6.852, P<0.001)$.

\section{Comparison of SDS before and after intervention}

Table 3 shows that the differences between SDS scores of the two groups before intervention are not statistically significant $(t=0.698, P=0.064)$. After 3 months of intervention, the SDS scores of the two groups were lower, and the differences between the corresponding values before intervention were statistically significant $(P<0.05)$. Their SAS scores also showed a significantly significant decrease $(t=4.899$, $P<0.001)$, larger in the HBM rehabilitation group than in the conventional rehabilitation group.

\section{Comparison of OP knowledge before and after intervention}

Table 4 shows that the OP knowledge scores of the two groups before intervention are not statistically significantly different $(t=1.818, P=0.071)$. After 3 months of intervention, the OP knowledge scores of the two groups are higher, and the differences with the corresponding values before intervention are statistically significant $(P<0.05)$; the increases in their OP knowledge scores, higher in the HBM rehabilitation group than in the conventional rehabilitation group, are statistically significantly different $(t=3.514, P<0.001)$.

\section{Comparison of OP health belief score before and after intervention}

Table 5 shows that the differences between OP health belief scores of the two groups before intervention are not statistically significant $(t=1.518, P=0.131)$. After 3 months of intervention, the OP knowledge scores of the two groups are higher, and the differences between the corresponding values before intervention are statistically significant $(P<0.05)$. Although both groups' OP health belief scores increased, the changes in scores in the HBM rehabilitation group were larger than in the conventional rehabilitation group, with statistical significance $(t=4.163, P<0.001)$. 


\section{DISCUSSION}

Fracture is often caused by a variety of accidental traumas. Facing a sudden limb immobilization, pain, worry about postoperative sequelae, and uncertainty about surgery, the patient usually suffers from many negative emotions. Studies have shown that orthopedic patients have a high incidence of depression, up to $56.8 \%$ in some cases, and this depression sometimes interacts with physical diseases, which can lead to suicidal behavior (Chen et al. 2005). In a study on the psychological stress and suicidal attitudes of 128 patients with fracture, anxiety and depression were found to be positively correlated with suicidal attitudes ( $\mathrm{Li}$ et al. 2012). Meanwhile, different rehabilitation guidance models differently affect the anxiety and depression of the patient with fracture. A more appropriate rehabilitation guidance model positively affects the patient, improving the patient's bad mood and postoperative healing of the wound.

\section{Effect of HBM rehabilitation exercises on negative emotions in elderly patients with osteoporotic fracture}

The results of this study show that the incidence rate of depression and anxiety in preoperative patients is higher than 59.3 \pm 7.9 , suggesting an extremely high incidence of emotional disorders, especially depression and anxiety, in elderly preoperative patients with osteoporotic fracture. After 3 months, the SDS and SAS scores of the HBM rehabilitation group are significantly lower than those before intervention, and the incidence of anxiety and depression was significantly decreased, suggesting that HBM rehabilitation exercises have a significant effect on the improvement of negative emotions, can relieve the patient's anxiety, depression, and other negative emotions, and ensure the patient's efficacy. This finding is consistent with the finding of Shang et al. (2011) in their research report. HBM can help patients understand the serious impact of their own negative emotions on postoperative orthopedic rehabilitation, know that eliminating negative emotions will be beneficial to postoperative orthopedic rehabilitation, and therefore establish the psychological self-regulation ability to actively cooperate in the treatment and develop a firm belief to overcome the disease. A study of applying HBM to COPM patients found that the negative emotions of the tested group of patients is lower than the control group because the tested group perceived the benefits of rehabilitation training, understood the seriousness of the disease, and were more willing to adhere to rehabilitation training and the implementation of health behaviors, so that their negative emotions caused by the disease were reduced (Ji \& Wang 2014). HBM considers patients' human and individual characteristics and uses professional psychological guidance and positive hints to effectively alleviate their negative emotions. Studies have shown that compared to traditional health education, HBM intervention is more effective in promoting patients' efficacy, improving their mood, and helping them become more active and hardworking during treatment (Reisi et al. 2014).

\section{Effect of HBM rehabilitation exercises on knowledge scores of elderly patients with osteoporotic fracture}

As found in the study, after 3 months of intervention, the OP knowledge scores of the two groups are higher; the increases in their OP knowledge scores, higher in the HBM rehabilitation group than in the conventional rehabilitation group, are statistically significantly different. Previous studies have revealed that the rehabilitation of elderly patients with osteoporotic fracture depends largely on early postoperative rehabilitation training. The patient can effectively increase the mobility of artificial joints through training, quickly reconstruct the muscles around the surgical site to restore the stability of the joints, and thereby improve their quality of life (Xu et al. 2017). However, some studies have demonstrated that many patients cannot bear the strong postoperative pain, and often suffer fear, depression, anxiety, and other negative emotions; they are reluctant to follow early rehabilitation training, failing to achieve the ideal rehabilitation effect (Zhou 2012). Many studies at home and abroad have confirmed that health education can significantly improve the OP knowledge level of patients (Zhou 2012). The two methods used in this study can also improve the OP knowledge of the elderly, indicating a more obvious effect in the HBM group. By examining the OP prevention effect among elderly people, Yang et al. (2009) found that traditional rehabilitation guidance and health belief rehabilitation guidance achieved no significant difference in OP knowledge. The inconsistency between this finding and the results of this study might be mainly related to the length of intervention. Yang et al. (2009) intervention lasted one month, but this study's intervention lasted three months. The longer intervention duration tends to result in more obvious effects among elderly patients with osteoporotic fracture. Secondly, the study by Yang Xiuling did not convey professional exercise knowledge to the elderly according to their physical conditions, which means that the exercise knowledge explained is not significantly different between the two groups. Hence, it is difficult to achieve different educational effects. In this study, when intervention was performed in elderly patients with fracture, the investigators emphasized the dangers of fracture complications, the benefits of healthy rehabilitation exercises, and the unintended consequences of refusing rehabilitation exercises. They helped patients build their confidence in the fight against the disease, affirmed and encouraged their correct rehabilitation exercise behaviors in a timely manner, discussed difficulties and solutions with the patients and their 
families to overcome unhelpful behaviors, and urged family members to monitor the patients to improve the patients' self-management behavior. The investigators designed rehabilitation exercise programs and implemented rehabilitation education measures, highlighted the patients' awareness of their susceptibility and the severity of the disease, affirmed the benefits of adherence to rehabilitation, analyzed difficulties and problems with the patients, and then worked together to develop a rehabilitation exercise plan. Studies have suggested that implementing healthy belief rehabilitation exercises enhances the patient's conscious awareness of health responsibilities and conscious behaviors to maintain and promote health (Mcdougall 2008), exposes the patient to more knowledge and information that is conducive to rehabilitation, and motivates them to accept and consciously implement self-management, thereby increasing the OP knowledge and OP health belief scores.

\section{Effect of HBM rehabilitation exercises on OP health beliefs in elderly patients with osteoporotic fracture}

Tussing et al. (2005) argued that health education can improve osteoporotic patients' susceptibility to calcium disorder and health beliefs; Sedlak's study (2000) found that health education increases the perceived movement disorders of osteoporosis. Based on an intervention with 280 elderly people in the community, the Chinese scholars Jiang et al. (2007) pointed out that health education can improve the perceived susceptibility to osteoporosis, calcium benefits, and health motivation, and reduce awareness of movement disorders. These results show that health education can affect the health beliefs of osteoporotic patients. In this study, the OP health belief scores of the two groups before intervention are not statistically significantly different $(t=1.518, P=0.131)$. After 3 months of intervention, the OP knowledge scores of the two groups are higher, and the differences between the corresponding values before intervention are statistically significant $(P<0.05)$; the increases in their OP health belief scores are statistically significantly different $(t=4.163, P<0.001)$. The results of this study are similar to those of previous studies, probably because of the perceived susceptibility. Perceived calcium disorder is a factor that affects the elderly to prevent OP. Therefore, due to the improved education in the rehabilitation guidance for the experiment group, the post-education level of perceived susceptibility and calcium disorder is higher in the experiment group than in the control group; the higher health motivation in the experiment group than in the control group may be attributed to the health education in the experiment group, especially the emphasis on susceptibility to OP. Noticeably, OP is a chronic disease that has no specific early symptoms; it can only be diagnosed through examination during hospitalization. Hence, when their perceived susceptibility to the disease increases in the experiment group, the patients would be more willing to follow the advice to maintain bone health, resulting in a corresponding increase in health motivation, so that the recurrence of elderly osteoporosis would be avoided or reduced.

\section{CONCLUSION}

Based on the methodology of epidemiological experiments, the study conducted a comparative experiment on 162 patients with osteoporotic fracture to compare the effect of traditional rehabilitation exercise guidance and HBM rehabilitation exercise guidance by evaluating the SAS, SDS, OP knowledge, and OP health belief scores of the two groups. This study sought to provide theoretical support for a more effective OP health education and rehabilitation exercise model for elderly patients with osteoporotic fracture.

- Although common, anxiety, depression, and other negative emotions in elderly patients with osteoporotic fracture undermine treatment and rehabilitation. Health care workers should attach great importance to this issue in the clinical treatment process to protect patients' treatment and rehabilitation.

- HBM rehabilitation exercises alleviate negative emotions in elderly patients with osteoporotic fracture and improve OP knowledge and OP health belief scores.

\section{Acknowledgements: None.}

\section{Conflict of interest: None to declare.}

\section{References}

1. Ang JB, Madsen JB: Imitation versus innovation in an aging society: international evidence since 1870. Journal of Population Economics 2015; 28:299-327.

2. Ballesta JAC: Mixed Care for Elderly People in Spain and France: A Comparative Analysis. Revista De Cercetare Si Interventie Sociala 2017; 57:89-103.

3. Burge R, Dawson-Hughes B, Solomon DH, Wong JB, King $A \&$ Tosteson A: Incidence and economic burden of osteoporosis related fractures in the united states, 2005-2025. Journal of Bone \& Mineral Research 2007; 22:465-475.

4. Chen YP, Liu XQ, Cai DH, Yang L, Li XY: Health Beliefs and Health Behaviors About Osteo Among the Middle abed and Elderly in Community. Journal of Nursing Science 2005; 20:62-63.

5. Hu YX, Wang Q, Meng PP, Qi MZ: Effect of motor imagery in addition to regular rehabilitation therapy on muscle strength of upper extremity in stroke patients. Progress in Modern Biomedicine 2009; 9:4512-4515.

6. Huang CY, Su HD, Liu SM: Effect of health belief model on improving self-care ability of elderly patients. Chinese Journal of Practical Nursing 2010, 26:65-66.

7. Huang SM, Li JX, Zhang XF, Wang QM, Wang J: Application effect of health belief model in health 
education for COPD patients. Journal of Nurses Training 2013; 28:1774-1776.

8. Ji M, Wang AH: Application effect of HBM in health education for patients with acute exacerbation of COPD accompanied by anxiety. Special Health 2014; 10:3-4.

9. Jiang XY, Zhang X: Study on the correlative issues between the mentors' instructions and the postgraduates' quality of culture. Chinese Journal of Nursing Education 2007; 42:105-109.

10. Kim KK, Horan ML, Gendler P, Patel MK: Development and evaluation of the Osteoporosis Health Belief Scale. Research in Nursing \& Health 1991; 14:155-163.

11. Li L, Ling M, Shang HH: Correlation between suicidal attitude and anxiety and depression in hospitalized fracture patients. Contemporary Medicine 2012; 18:81-83.

12. Lupescu O, Marcov N: Assessment of Awareness Regarding Osteoporosis Prevention in a Group of PreMenopause Women. Revista de Cercetare si Interventie Sociala 2016; 55:127-138.

13. Mcdougall J: Landfill modelling challenge: HBM model predictions. Waste \& Resource Management 2008; 161:147-153

14. Reisi M, Javadzade SH, Shahnazi H, Sharifirad G, Charkazi A \& Moodi M: Factors affecting cigarette smoking based on health-belief model structures in preuniversity students in Isfahan, Iran. Journal of Education \& Health Promotion 2014; 3:23.

15. Rosenstock IM: Historical Origins of the Health Belief Model. Health Education Monographs 1974; 2:328-335.

16. Sedlak CA, Doheny MO, Jones SL: Osteoporosis education programs: changing knowledge and behaviors. Public Health Nursing 2000; 17:398-402.

17. Sha Y: Research on the supply of basic public services under the trend of population aging - Taking Jiangsu Province as an example. Jiangsu Social Sciences 2016; 2:236-241.

18. Shang H: Nursing care of elderly patients with femoral neck fracture treated with artificial femoral head replacement. China Medical Engineering 2011; 1:149-149.
19. Srichuae S, Nitivattananon V, Perera R: Aging society in Bangkok and the factors affecting mobility of elderly in urban public spaces and transportation facilities. Iatss Research 2016; 40:26-34.

20. Straub CL, Leahy JE: Application of a Modified Health Belief Model to the Pro Environmental Behavior of Private Well Water Testing. Jawra Journal of the American Water Resources Association 2015; 50:1515-1526.

21. Sun KG, Zhang XX, Wu SY, Yang SS, He C, Li YD, et al.: Application of health belief model to explore exercise behavior and its influencing factors in patients with hypertension. Chinese Journal of Health Education 2016; 32:414-418.

22. Tussing L, Chapman-Novakofski K: Osteoporosis prevention education: Behavior theories and calcium intake. Journal of the American Dietetic Association 2005; 105:92-97.

23. Wang D, Liu N, Gao Y, Li P \& Tian M: Association between metabolic syndrome and osteoporotic fracture in middle-aged and elderly chinese peoples. Cell Biochemistry \& Biophysics 2014; 70:1297-1303.

24. Wang LJ, Song CP, Xiao L: Analysis of influencing factors and rehabilitation nursing of senile osteoporotic fracture. Journal of Nurses Training 2010; 25:2250-2252.

25. Xu ZJ, Cui YC, Lv C, Wu YY, Cai Y, Shen T: Health behavior intervention models and theories for osteoporosis patients. Journal of Shanghai Jiaotong University 2017; 37:118-121.

26. Yang XL, Wang CM, Yang CP: Related factors of osteoporosis prevention behaviors in women. Journal of Tianjin Medical University 2009; 15:213-215.

27. Zhou YW: Effect of nursing intervention on postoperative anxiety and depression in patients with fracture. Chinese Journal of Primary Medicine and Pharmacy 2012; 19:3838-3839.

28. Zung WW: A rating instrument for anxiety disorders. Psychosomatics 1971; 12:371-379.

29. Zung $W W$ : A self-rating depression scale. Archives of general psychiatry 1965; 12:63-70.

Correspondence:

Ming Zhang, MD

Department of Physical Education, Nanjing Sport Institute

Nanjing 210014, Jiangsu Province, China

E-mail: mingzhang2014@yeah.net 